\title{
Manajemen Pemupukan Tanaman Kelapa Sawit (Elaeis guineensis Jacq.) di Kebun Rambutan Sumatera Utara
}

Fertilization Management Oil Palm Plant (Elaeis guineensis Jacq.) in Kebun Rambutan North Sumatera

\section{Rian Herdiansah dan Adolf Pieter Lontoh*}

Departemen Agronomi dan Hortikultura, Fakultas Pertanian, Institut Pertanian Bogor (Bogor Agricultural University), Jl. Meranti, Kampus IPB Darmaga, Bogor 16680, Indonesia Telp. \& Faks. 0251-8629353 e-mail: agronipb@indo.net.id

"Penulis untuk korespondensi : alfpiton@yahoo.com

Disetujui : 14 Mei 2018 / Published Online 21 Mei 2018

\begin{abstract}
Oil palm is a crop of foreign exchange for Indonesia, so special efforts are needed to increase palm oil production. Increased production can be done with the management of palm oil fertilization on plantations. The research activities kept in February 6th until June 5 th 2017 in Kebun Rambutan North Sumatera. This research aims to improve the knowledge and experiences of student in oil palm cultivation aspects for generally and for specifically to study the management of oil palm crop fertilization in Kebun Rambutan North Sumatera. The research activities include a technical aspect as freelance emloyess (KHL) and managerial aspect as co-foreman and co-assistant. Observation include 5T rules (right type, right dose, right way, right place, right time), losses fertilizer losses) and fertilizer workers perfomance. The results observation in yield compared to the Standart Departement of the company. The obtained data analyzed qualitatively and quantitatively with descriptive analysis method, finding the average, the percentage of observations, and t-student test. Fertilization activity in Rambutan Garden is good enough because it meets company standards up to 90\%. The realization of fertilizer time does not met the standards because Urea, $R P$, Borate, MOP and Kiserit does not been applied in the field. The average accuracy of fertilizer place is $168.50 \mathrm{~cm}$. The value is lower than the company standard of $175 \mathrm{~cm}$.
\end{abstract}

Keywords: dose, place, time, treatmen, type

ABSTRAK

Kelapa sawit merupakan tanaman penghasil devisa bagi Indonesia, sehingga diperlukan upaya khusus untuk meningkatkan produksi kelapa sawit. Peningkatan produksi dapat dilakukan dengan manajemen pemupukan kelapa sawit pada perkebunan. Kegiatan penelitian dilaksanakan mulai 06 Februari hingga 05 Juni 2017 di Kebun Rambutan Sumatera Utara. Kegiatan penelitian bertujuan untuk meningkatkan pengetahuan dan pengalaman mahasiswa dalam aspek budidaya tanaman kelapa sawit secara umum dan secara khusus untuk mempelajari manajemen pemupukan tanaman kelapa sawit yang terdapat di Kebun Rambutan Sumatera Utara. Kegiatan penelitian yang dilakukan meliputi aspek teknis sebagai karyawan harian lepas (KHL) dan aspek manajerial sebagai pendamping mandor serta pendamping asisten. Pengamatan yang dilakukan meliputi kaidah 5T ( tepat jenis, tepat dosis, tepat cara, tepat tempat, tepat waktu), losses (kehilangan pupuk) dan prestasi kerja penabur. Hasil pengamatan yang didapat di lapang dibandingkan dengan standar dari Departemen Riset Perusahaan. Data yang diperoleh dianalisis secara kualitatif dan kuantitatif dengan metode analisis deskriptif, mencari rata-rata, persentase hasil pengamatan, dan menggunakan uji t-student. Kegiatan pemupukan di Kebun Rambutan sudah cukup baik karena sudah memenuhi standar perusahaan hingga 90\%. Realisasi waktu pemupukan belum memenuhi standar karena pupuk Urea, RP, Borate, MOP dan Kiserit belum di aplikasikan di lapangan. Rata-rata ketepatan tempat pemupukan sebesar $168,50 \mathrm{~cm}$. Nilai tersebut lebih rendah dari standar perusahaan $175 \mathrm{~cm}$.

Kata kunci : cara, dosis, jenis, tempat, waktu 


\section{PENDAHULUAN}

Kelapa sawit sebagai tanaman penghasil minyak sawit dan inti sawit merupakan salah satu primadona tanaman perkebunan yang menjadi sumber penghasil devisa non migas bagi Indonesia. Prospek minyak kelapa sawit yang terus meningkat dalam perdagangan minyak nabati dunia telah mendorong pemerintah Indonesia untuk memacu pembangunan areal perkebunan kelapa sawit (Masykur, 2013). Hal tersebut terbukti dari luas lahan perkebunan kelapa sawit di Indonesia pada tahun 2012 adalah 10133.32 ha, sedangkan pada tahun 2013 menjadi 10465.02 ha. Produksi minyak kelapa sawit (CPO) Indonesia tahun 2012 adalah 26015.52 ton yang mengalami peningkatan dibandingkan dengan tahun 2013 menjadi 27782 ton (BPS, 2014). Produksi CPO yang terus meningkat setiap tahun menyebabkan Indonesia menjadi salah satu pengekspor CPO terbesar di dunia. Produktivitas kelapa sawit Indonesia tahun 2014 adalah $3601 \mathrm{~kg}$ $\mathrm{ha}^{-1}$ dan mengalami peningkatan pada tahun 2015 menjadi $3679 \mathrm{~kg} \mathrm{ha}^{-1}$ (Ditjenbun, 2015).

Peningkatan produktivitas menjadi alternatif untuk mengembangkan produksi kelapa sawit di Indonesia. Produktivitas kelapa sawit dapat ditingkatkan dengan berbagai cara, misalnya melalui kegiatan pemeliharaan. Kegiatan pemeliharaan tanaman kelapa sawit meliputi sanitasi tanaman, pengendalian hama dan penyakit, pengendalian gulma, konservasi tanah, penunasan, pengambilan contoh daun dan pemupukan.

Pemupukan merupakan suatu kegiatan penambahan unsur hara yang dibutuhkan oleh tanaman guna menunjang pertumbuhan dan perkembangan tanaman. Tanaman kelapa sawit membutuhkan unsur hara makro dan mikro dalam jumlah yang cukup berimbang. Pemberian unsur hara mikro melalui injeksi infus akar pada akarakar yang aktif tumbuh. Unsur hara makro pada tanaman kelapa sawit diberikan melalui pupuk kimia (anorganik) dengan cara ditabur pada piringan (Bahari, 2010). Pemupukan kelapa sawit harus dilakukan secara berkesinambungan untuk mendukung produktivitas tanaman yang cukup tinggi. Hal tersebut disebabkan tanaman kelapa sawit tergolong tanaman yang sangat memerlukan unsur hara.

Pemupukan sangat penting bagi pertumbuhan dan perkembangan tanaman. Tanaman menyerap unsur hara berasal dari tanah dan pupuk yang diaplikasikan. Hal-hal yang menjadi alasan dilakukan pemupukan yaitu tanah tidak mampu menyediakan hara yang cukup bagi tanaman, tanaman kelapa sawit membutuhkan hara yang banyak untuk mencapai produksi yang tinggi, penggunaan varietas unggul memerlukan hara yang lebih banyak, unsur hara yang terangkut berupa produksi tidak semua dikembalikan ke dalam tanah (Saputra, 2011).

Keefektifan pemupukan berhubungan dengan tingkat atau persentase hara pupuk yang diserap tanaman. Pemupukan dikatakan efektif jika sebagian besar hara pupuk diserap tanaman. Efisiensi pemupukan sangat berkaitan antara biaya (bahan pupuk, alat kerja dan upah) dengan tingkat produksi yang dihasilkan, selain itu efisiensi pemupukan juga berkaitan dengan tindakan rekomendasi pemupukan dan manajemen operasional. Peningkatan keefektifan dan efisiensi pemupukan dapat dicapai melalui perbaikan manajemen operasional dan rekomendasi pemupukan (Saputra, 2011). Kegiatan penelitian ini bertujuan untuk meningkatan pengetahuan dan pengalaman mahasiswa dalam aspek budidaya tanaman kelapa sawit secara umum. Tujuan secara khusus pada penelitian ini adalah untuk mempelajari manajemen pemupukan tanaman kelapa sawit yang terdapat di Kebun Rambutan Sumatera Utara.

\section{METODE PENELITIAN}

Kegiatan penelitian dilakukan di Kebun Rambutan Sumatera Utara. Kegiatan penelitian dilaksanakan selama empat bulan yang dimulai bulan Februari hingga Juni 2017.

Kegiatan penelitian yang dilakukan yaitu kegiatan teknis di lapangan dan kegiatan manajerial baik di perkebunan maupun di kantor. Kegiatan-kegiatan tersebut dilakukan sesuai dengan waktu dan jadwal yang ditentukan oleh pihak perkebunan. Praktek kerja di lapangan dilakukan dengan mengikuti pelaksanaan kegiatan perkebunan, wawancara, dan diskusi dengan mandor maupun dengan staf.

Kegiatan penelitian yang dilakukan adalah karyawan harian lepas (KHL) selama empat minggu, pendamping mandor pada empat minggu berikutnya, dan pendamping asisten kebun pada delapan minggu berikutnya. Kegiatan teknis lapang yang dilakukan adalah pengendalian gulma, pemupukan, dan panen. Aspek manajerial didapatkan saat menjadi pendamping mandor dan asisten, serta berkonsultasi dengan manajer selama pelaksanaan penelitian. Aspek manajerial yang dilakukan adalah fungsi-fungsi manajemen, tugas pokok, kewenangan dan tanggung jawab ditingkat mandor, krani produksi, krani afdeling, dan asisten di perkebunan. 
Pengumpulan data yang dilakukan meliputi pengambilan data primer dan data sekunder. Data primer merupakan informasi yang diperoleh secara langsung melalui pengamatan yang dilakukan di lapangan maupun diskusi langsung dengan KHL, mandor, dan asisten kebun. Data primer meliputi keefektifan pemupukan (tepat jenis, dosis, cara, waktu, dan tempat), serta prestasi kerja penabur. Data sekunder diperoleh dari studi pustaka dan mempelajari arsip kebun, laporan bulanan, laporan tahunan, serta dokumentasi kebun. Jenis data yang diperoleh adalah sejarah dan kondisi umum perusahaan, kondisi iklim, kondisi tanaman, organisasi manajemen perusahaan, data produksi kebun, dan data realisasi pemupukan selama tahun 20162017. Berikut ini adalah rincian pengumpulan data primer:

1. Ketepatan jenis pupuk. Pengamatan realisasi jenis pupuk yang diaplikasikan di lapangan dibandingkan dengan standar perusahaan.

2. Ketepatan dosis pupuk. Pengamatan ini dilakukan terhadap dosis per tanaman dengan menghitung jumlah taburan per tanaman yang dibandingkan dengan standar perusahaan. Pengambilan contoh tanaman dilakukan pada 5 orang penabur dengan 3 kali ulangan (blok sebagai ulangannya). Masing-masing penabur diambil 15 contoh tanaman yang diamati.

3. Ketepatan cara pemupukan. Pengamatan cara penaburan pupuk yang dilakukan oleh penabur yang dibandingkan dengan standar perusahaan. Pengambilan contoh tanaman dilakukan pada 5 orang penabur dengan 3 kali ulangan (blok sebagai ulangannya). Masing-masing penabur diambil 15 contoh tanaman yang diamati.

4. Ketepatan tempat pemupukan. Pengamatan tempat penaburan pupuk yang dilakukan oleh tenaga penabur. Pengamatan dilakukan dengan mengukur jarak penabur pupuk dari batang tanaman kelapa sawit yang dibandingkan dengan standar perusahaan. Pengambilan contoh tanaman dilakukan pada 5 orang penabur dengan 3 kali ulangan (blok sebagai ulangannya). Masing-masing penabur diambil 15 contoh tanaman yang diamati.

5. Ketepatan waktu pemupukan. Realisasi waktu pemupukan dibandingkan dengan standar perusahaan.

6. Kehilangan pupuk. Pengamatan kehilangan pupuk dari gudang hingga ke Supply point besar dan dari Supply point besar hingga ke Supply point kecil. Pengambilan contoh dilakukan dengan 3 kali ulangan (truk sebagai ulangannya).

7. Prestasi kerja penabur. Pengamatan jumlah pupuk yang diecer ke lahan dan diaplikasikan, jumlah penabur, dan luas yang teraplikasikan. Hasil pengamatan dibandingkan dengan standar perusahaan.

Data primer dan sekunder yang dihasilkan dianalisis secara kualitatif dan kuantitatif dengan metode analisis deskriptif, mencari rata-rata, presentase hasil pengamatan, dan menggunakan uji $t$-student. Data kemudian diuraikan secara deskriptif dengan membandingkan antara norma baku perkebunan kelapa sawit secara umum dengan standar perusahaan, atau studi pustaka.

$$
\begin{aligned}
& \text { Thitung }=\frac{\overline{X_{1}}-\overline{X_{2}}}{\overline{S_{p \frac{1}{n_{1}}+\frac{1}{n_{2}}}}} \\
& \text { dengan } S p=\frac{\overline{n-1 S_{1}^{2}+(n-1) S_{2}^{2}}}{n_{1}+n_{2}-2}
\end{aligned}
$$

Keterangan:

$\mathrm{X}_{1}$ dan $\mathrm{X}_{2} \quad$ : nilai contoh 1 dan 2

$S_{1}^{2}$ dan $S_{2}^{2} \quad$ : ragam contoh 1 dan 2

$\mathrm{n}_{1}$ dan $\mathrm{n}_{2} \quad$ : jumlah contoh 1 dan 2

$\mathrm{Sp} \quad$ : simpangan baku gabungan

Nilai beda nyata apabila $t$ hit. $>t$ tabel dan tidak berbeda nyata apabila $\mathrm{t}$ hit. $<\mathrm{t}$ tabel diperoleh dari nilai sebaran t pada taraf $5 \%$ dan $\mathrm{db}$ $(\mathrm{n} 1+\mathrm{n} 2-2)($ Walpole, 1995).

\section{HASIL DAN PEMBAHASAN}

Pelaksanaan kegiatan pemupukan tanaman kelapa sawit harus memperhatikan konsep 5T (tepat jenis, tepat dosis, tepat waktu, tepat cara, dan tepat tempat), losses, dan prestasi kerja penabur. Penentuan konsep 5T pada pelaksanaan pemupukan di Kebun Rambutan Sumatera Utara berdasarkan analisis daun, analisis tanah, dan kebijakan perusahaan.

\section{Ketepatan Jenis Pupuk}

Jenis pupuk untuk tanaman kelapa sawit dapat dikelompokkan ke dalam lima kelompok yaitu pupuk tunggal, pupuk campuran, pupuk majemuk, pupuk lambat tersedia (tablet) dan pupuk organik. Jenis pupuk yang direkomendasikan PPKS dalam penyusunan rekomendasi pemupukan tanaman kelapa sawit adalah Urea (pupuk N), Rock phosphate (RP) atau 
SP-36 (pupuk P), Muriate of potash (MOP) (pupuk K), Dolomit atau Kiserit (pupuk Mg) dan pupuk HGF-Borate (pupuk B). Pemilihan jenis pupuk harus memenuhi SNI (Standar Nasional Indonesia) karena telah banyak jenis pupuk yang beredar di pasar yang tidak memenuhi SNI (Winarna et al., 2007).

Jenis pupuk yang direkomendasikan Kebun Rambutan berbeda antara tanaman belum menghasilkan (TBM) dengan tanaman menghasilkan (TM). TBM kelapa sawit menggunakan pupuk tunggal seperti Urea, Rock phospate, Borate, MOP dan Kiserit, sedangkan TM kelapa sawit pupuk yang digunakan hanya pupuk NPK Palmo dan Dolomit. Jenis pupuk rekomendasi Kebun Rambutan telah sesuai dengan jenis pupuk yang direkomendasikan PPKS sesuai Standar Nasional Indonesia. Hasil pengamatan realisasi ketepatan jenis pupuk di Kebun Rambutan dapat dilihat pada Tabel 1.

Berdasarkan data pengamatan pada Tabel 1, jenis pupuk yang digunakan untuk TM kelapa sawit telah sesuai dengan jenis pupuk rekomendasi kebun. Jenis pupuk yang diaplikasikan di lapang untuk TBM kelapa sawit berbeda dengan jenis pupuk rekomendasi. Jenis pupuk yang direkomendasikan yaitu pupuk Rock phospate dengan kandungan minimal 28\% P2O5 (total), minimal 10\% P2O5 (asam sitrat), minimal $40 \% \mathrm{Ca}+\mathrm{Mg}$, maksimal $3 \% \mathrm{Al} 2 \mathrm{O} 3+\mathrm{Fe} 2 \mathrm{O} 3$ dan maksimal 3\% $\mathrm{H} 2 \mathrm{O}$, tetapi saat aplikasi di lapang pupuk yang digunakan adalah TSP dengan kandungan $46 \%$ P2O5. Hal ini disebabkan pembelian pupuk TSP oleh perusahaan, sehingga pupuk tersebut yang diaplikasikan di lapang. Perusahaan diperbolehkan membeli pupuk dengan jenis berbeda dari pupuk rekomendasi dengan syarat memiliki fungsi dan kandungan yang dapat menggantikan jenis pupuk rekomendasi. Penggunaan dosis pupuk TSP di lapangan sama dengan dosis rekomendasi pupuk RP yaitu 700 g. Kandungan P2O5 total pupuk RP $28 \%$, sehingga penggunaan dosis TSP seharusnya lebih rendah karena kandungan P2O5 TSP lebih tinggi yaitu $46 \%$. Penggunaan dosis TSP yang sesuai dengan dosis rekomendasi RP termasuk pemborosan pupuk dan dapat merugikan perusahaan.

Tabel 1. Rekomendasi dan realisasi jenis pupuk di Kebun Rambutan 2017

\begin{tabular}{|c|c|c|c|c|c|c|c|}
\hline \multicolumn{4}{|c|}{ Rekomendasi } & \multicolumn{4}{|c|}{ Realisasi } \\
\hline Jenis Pupuk & Unsur hara & Kandungan & Dosis $(\mathrm{kg})$ & Jenis Pupuk & Unsur hara & Kandungan & Dosis $(\mathrm{kg})$ \\
\hline \multicolumn{8}{|l|}{$\mathrm{TM}$} \\
\hline NPK & $\mathrm{N}$ & $14 \%$ & 2.5 & NPK & $\mathrm{N}$ & $14 \%$ & 2.5 \\
\hline \multirow[t]{4}{*}{ Palmo } & $\mathrm{P}_{2} \mathrm{O}_{5}$ & $9 \%$ & & Palmo & $\mathrm{P}_{2} \mathrm{O}_{5}$ & $9 \%$ & \\
\hline & $\mathrm{K}_{2} \mathrm{O}$ & $22 \%$ & & & $\mathrm{~K}_{2} \mathrm{O}$ & $22 \%$ & \\
\hline & $\mathrm{MgO}$ & $2 \%$ & & & $\mathrm{MgO}$ & $2 \%$ & \\
\hline & $\mathrm{TE}$ & $1 \%$ & & & $\mathrm{TE}$ & $1 \%$ & \\
\hline \multirow[t]{6}{*}{ Dolomit } & $\mathrm{MgO}$ & $18-24 \%$ & 2.5 & Dolomit & $\mathrm{MgO}$ & $18-24 \%$ & 2.5 \\
\hline & $\mathrm{CaO}$ & $30 \%$ & & & $\mathrm{CaO}$ & $30 \%$ & \\
\hline & $\mathrm{Al}_{2} \mathrm{O}_{3}$ & $\min 3 \%$ & & & $\mathrm{Al}_{2} \mathrm{O}_{3}$ & $\min 3 \%$ & \\
\hline & $+\mathrm{Fe}_{2} \mathrm{O}_{3}$ & & & & $+\mathrm{Fe}_{2} \mathrm{O}_{3}$ & & \\
\hline & $\mathrm{SiO}_{2}$ & $\min 3 \%$ & & & $\mathrm{SiO}_{2}$ & $\min 3 \%$ & \\
\hline & Kadar air & $\min 1 \%$ & & & Kadar air & $\min 1 \%$ & \\
\hline \multicolumn{8}{|l|}{ TBM } \\
\hline Urea & $\mathrm{N}$ & $46 \%$ & 1 & Urea & $\mathrm{P}_{2} \mathrm{O}_{5}$ & $46 \%$ & 1 \\
\hline \multirow[t]{5}{*}{$\mathrm{RP}$} & $\mathrm{P}_{2} \mathrm{O}_{5}$ (total) & $\min 28 \%$ & 0.7 & TSP & $\mathrm{P}_{2} \mathrm{O}_{5}$ & $46 \%$ & 0.7 \\
\hline & $\begin{array}{c}\mathrm{P}_{2} \mathrm{O}_{5} \text { (asam } \\
\text { sitrat) }\end{array}$ & $\min 10 \%$ & & & & & \\
\hline & $\mathrm{Ca}+\mathrm{Mg}$ & $\min 40 \%$ & & & & & \\
\hline & $\begin{array}{c}\mathrm{Al}_{2} \mathrm{O}_{3}+ \\
\mathrm{Fe}_{2} \mathrm{O}_{3}\end{array}$ & maks $3 \%$ & & & & & \\
\hline & $\mathrm{H}_{2} \mathrm{O}$ & maks $3 \%$ & & & & & \\
\hline Borate & $\mathrm{B}_{2} \mathrm{O}_{5}$ & $\min 45 \%$ & 0.01 & Borate & \multicolumn{3}{|c|}{ Belum dipupuk Belum dipupuk Belum dipupuk } \\
\hline MOP & $\mathrm{K}_{2} \mathrm{O}$ & $\min 60 \%$ & 1 & MOP & \multirow{3}{*}{\multicolumn{3}{|c|}{$\begin{array}{l}\text { Belum dipupuk Belum dipupuk Belum dipupuk } \\
\text { Belum dipupuk Belum dipupuk Belum dipupuk }\end{array}$}} \\
\hline Kiserit & $\mathrm{MgO}$ & $\min 26 \%$ & 0.4 & Kiserit & & & \\
\hline & $\mathrm{S}$ & $\min 21 \%$ & & & & & \\
\hline
\end{tabular}


Tabel 2. Ketepatan dosis pemupukan NPK Palmo di Kebun Rambutan 2017

\begin{tabular}{cccccc}
\hline \multirow{2}{*}{ Ulangan } & $\begin{array}{c}\text { N Tanaman yang } \\
\text { diamati (pohon) }\end{array}$ & $\begin{array}{c}\text { Dosis pertanaman } \\
(\mathrm{kg})\end{array}$ & $\begin{array}{c}\text { Dosis tidak } \\
\text { sesuai (pohon) }\end{array}$ & $\begin{array}{c}\text { Tidak tepat } \\
\text { dosis }(\%)\end{array}$ & $\begin{array}{c}\text { Tepat dosis } \\
(\%)\end{array}$ \\
\hline 1 & 75 & 2.50 & 7 & 9.33 & 90.67 \\
2 & 75 & 2.50 & 8 & 10.67 & 89.33 \\
3 & 75 & 2.50 & 3 & 4.00 & 96.00 \\
\hline Rata-rata & & & 6 & 8.00 & 92.00 \\
\hline
\end{tabular}

\section{Ketepatan Dosis Pupuk}

Kemampuan tanah dalam menyediakan hara tergantung pada jumlah hara yang tersedia, adanya fiksasi dan mobilisasi, serta tersedianya hara pada zona perakaran (Pahan, 2010). Penentuan dosis pemupukan dilakukan dengan berbagai pertimbangan yaitu analisis leaf sampling unit (LSU), historis status hara daun, produksi, umur tanaman, jenis tanah, pengamatan visual, dan nilai ekonomis (Ryanto, 2012). Menurut Pahan (2007) Pertimbangan yang digunakan dalam menentukan dosis pupuk agar mengimbangi defisiensi hara dalam tanah meliputi hasil analisis daun dan tanah, realisasi produksi lima tahun sebelumnya, realisasi pemupukan tahun sebelumnya, data curah hujan minimal lima tahun terakhir, dan hasil pengamatan lapangan yang meliputi defiensi hara, kultur teknis, dan panen.

Dosis pupuk yang direkomendasikan Kebun Rambutan berbeda antara tanaman belum menghasilkan (TBM) dengan tanaman menghasilkan (TM). Dosis pupuk TBM mengacu pada dosis baku (berdasarkan umur tanaman), sedangkan dosis TM berdasarkan hasil analisis daun, analisis tanah dan realisasi pemupukan tahun sebelumnya. Alat yang digunakan penabur adalah mangkok yang telah dikalibrasi. Satu mangkok berisi $0.5 \mathrm{~kg}$ pupuk NPK Palmo. Dosis pemupukan NPK palmo $2.5 \mathrm{~kg}$ tanaman $^{-1}$, sehingga diperlukan 5 mangkok pupuk tanaman1. Apabila jumlah pupuk yang diberikan kurang atau lebih dari 5 mangkok maka dapat dinyatan tidak tepat dosis. Hasil pengamatan tepat dosis dapat dilihat pada Tabel 2.

Berdasarkan data pengamatan yang dilakukan pada Tabel 2, ketepatan dosis pemupukan NPK Palmo mencapai 92\% dengan rata-rata tidak tepat dosis $8 \%$. Data tersebut telah memenuhi standar perusahaan yaitu $\geq 90 \%$. Nilai rata-rata ketidaktepatan dosis $8 \%$ disebabkan oleh penabur yang tidak mengisi takaran (mangkok) dengan penuh atau hanya memperkirakannya saja. Hal ini dikarenakan kurangnya pengawasan dari mandor pupuk. Ketepatan dosis juga dipengaruhi oleh faktor subyetivitas dari penabur, sehingga sangat penting untuk terus memberikan pengarahan dan pengawasan dalam proses pemupukan.

\section{Ketepatan Waktu Pemupukan}

Menurut Pahan (2007) waktu dan frekuensi pemupukan dipengaruhi oleh iklim terutama curah hujan, sifat fisik tanah, pengadaan pupuk, serta adanya sifat sinergis dan antagonis antar unsur hara. Pemupukan dapat diserap secara maksimal oleh tanaman apabila curah hujan 100$250 \mathrm{~mm}$ bulan $^{-1}$. Kondisi ini menunjukan tanah cukup basah tetapi belum jenuh, sehingga memudahkan terserapnya unsur hara oleh tanaman. PPKS (2005) menyatakan curah hujan minimum untuk pemupukan yaitu $60 \mathrm{~mm}$ bulan $^{-1}$ dan curah hujan maksimum $300 \mathrm{~mm}^{\text {bulan }}{ }^{-1}$.

Rekomendasi waktu pemupukan di Kebun Rambutan didasarkan pada curah hujan dan pengadaan pupuk. Pemupukan dapat dilakukan apabila curah hujan minimal $60 \mathrm{~mm}$ bulan $^{-1}$. Data curah hujan Januari-Mei 2017 dan data pengamatan tepat waktu dan dapat dilihat pada Tabel 3 dan 4.

Tabel 3. Curah hujan di Kebun Rambutan pada Januari-Mei 2017

\begin{tabular}{lc}
\hline Bulan & Curah hujan $\left(\mathrm{mm} \mathrm{bulan}^{-1}\right)$ \\
\hline Januari & 100 \\
Februari & 82 \\
Maret & 143 \\
April & 67 \\
Mei & 112 \\
\hline Rata-rata & 100.8 \\
\hline Sumber: Laporan pemupukan Afdeling I Kebun Rambutan, \\
&
\end{tabular}

Berdasarkan hasil pengamatan pada Tabel 3, rata-rata curah hujan Kebun Rambutan dari bulan Januari-Mei 2017 yaitu $100.8 \mathrm{~mm}_{\text {bulan }}{ }^{-1}$. Data tersebut telah memenuhi standar curah hujan minimal untuk dilakukan pemupukan. Curah hujan untuk pemupukan di kebun tersebut sesuai dengan standar curah hujan minimum yang direkomendasikan oleh Pusat Penelitian Kelapa sawit (PPKS). 
Tabel 4. Rencana dan realisasi pemupukan di Kebun Rambutan

\begin{tabular}{|c|c|c|c|c|c|c|c|c|c|c|}
\hline \multirow{3}{*}{ Jenis Pupuk } & \multicolumn{5}{|c|}{ Rencana pemupukan } & \multicolumn{5}{|c|}{ Realisasi pemupukan } \\
\hline & \multicolumn{10}{|c|}{ Bulan aplikasi } \\
\hline & Jan & Feb & Mar & Apr & Mei & Jan & Feb & Mar & Apr & Mei \\
\hline & \multicolumn{10}{|c|}{ TM } \\
\hline $\begin{array}{l}\text { NPK Palmo } \\
\text { Dolomit }\end{array}$ & & & & & & & & & & \\
\hline
\end{tabular}

$\begin{array}{ll}\text { RP } & \\ \text { Urea } & \\ \text { Borate } \\ \text { MOP } \\ \text { Kiserit }\end{array}$

Keterangan:

Rencana pemupukan TM

Rencana pemupukan TBM 2014

Rencana pemupukan TBM 2016
TBM

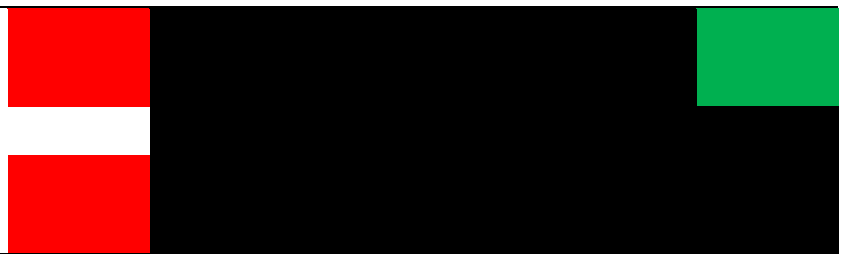

Berdasarkan bulan aplikasi pada Tabel 4 . Hasil pengamatan menunjukkan adanya ketidaktepatan realisasi waktu pemupukan pada tanaman belum menghasilkan (TBM). Seluruh jenis pupuk pada TBM 2016 mengalami ketidaktepatan waktu pemupukan, sedangkan pada TBM 2014 hanya pada pupuk MOP dan Kiserit. Hal ini disebabkan oleh keterlambatan pengadaan pupuk di Kebun Rambutan, sehingga berdampak terhadap ketidaktepatan waktu pemupukan di lapang. Penyelesaian masalah dapat dilakukan dengan merencanakan kontrak pengadaan pupuk sebaik mungkin termasuk memperhitungkan waktu pengiriman, sehingga pupuk dapat tersedia tepat waktu.

\section{Ketepatan Cara Pemupukan}

Cara pemupukan yang umum digunakan yaitu disebar di atas tanah, di dalam rorak-rorak (parit), benam, langsung dimasukan ke dalam batang dan follat spray melalui daun (Hakim, 2007). Cara pemupukan yang direkomendasikan
PPKS yaitu menebar $\mathrm{P}, \mathrm{K}$ dan $\mathrm{Mg}$ di piringan dan membenamkan $\mathrm{N}$ di dalam tanah. Pemupukan dengan pembenaman dalam tanah juga dilakukan pada daerah miring yang belum memiliki tapak kuda (Winarna et al., 2007).

Cara pemupukan di Kebun Rambutan ditentukan berdasarkan jenis pupuk. Pupuk NPK Palmo diaplikasikan dengan cara dibenamkan dalam tanah (pocket), sedangkan jenis pupuk tunggal seperti Urea, RP, Dolomit, Kiserit dan MOP diaplikasikan dengan cara ditabur pada piringan. Aplikasi dengan cara pocket dilakukan pada empat titik disekitar piringan, sedangkan penaburan pupuk dilakukan merata melingkar tanaman kelapa sawit. Pengaplikasian pupuk dengan cara tabur maupun pocket memiliki keunggulan masing-masing. Keunggulan sistem tabur yaitu lebih mudah dan murah karena tidak mengeluarkan biaya untuk membuat lubang pocket. Keunggulan sistem pocket yaitu untuk meminimalisir kehilangan unsur hara akibat pencucian dan penguapan. Hasil pengamatan tepat cara dapat dilihat pada Tabel 5.

Tabel 5. Ketepatan cara pemupukan Urea dan NPK Palmo di Kebun Rambutan

\begin{tabular}{cccccc}
\hline Ulangan & Jenis pupuk & $\begin{array}{c}\sum \text { Tanaman yang diamati } \\
\text { (pohon) }\end{array}$ & $\begin{array}{c}\sum \text { Tanaman tidak tepat } \\
\text { cara (pohon) }\end{array}$ & Tidak tepat cara (\%) Tepat cara (\%) \\
\hline 1 & Urea & 75 & 7 & 9.33 & 90.67 \\
2 & Urea & 75 & 3 & 4.00 & 96.00 \\
3 & Urea & 75 & 9 & 12.00 & 88.00 \\
\hline Rata-rata & & & & 8.44 & 91.56 \\
\hline 1 & NPK Palmo & 75 & 5 & 6.67 & 93.33 \\
2 & NPK Palmo & 75 & 7 & 9.33 & 90.67 \\
3 & NPK Palmo & 75 & 6 & 8.00 & 92.00 \\
\hline Rata-rata & & & & 8.00 & 92.00 \\
\hline
\end{tabular}


Berdasarkan pengamatan pada Tabel 5, ketepatan cara pemupukan Urea dan NPK Palmo sudah cukup baik. Ketepatan cara pemupukan Urea mencapai $91.56 \%$ sedangkan NPK Palmo 92\%. Data tersebut telah memenuhi standar perusahaan yaitu $\geq 90 \%$. Ketidaktepatan cara pemupukan Urea sebesar $8.44 \%$ sedangkan NPK Palmo 8\%. Hal ini disebabkan oleh kurangnya kemampuan penabur dalam mengaplikasikan pupuk. Penyelesaian masalah dapat dilakukan dengan memberikan pengarahan dan pengawasan kepada penabur sebelum aplikasi pemupukan.

\section{Ketepatan Tempat Pemupukan}

Tempat pengaplikasian pupuk yang baik pada tanaman kelapa sawit yaitu melalui daun, piringan, akar dan larikan (Pahan, 2007). Menurut Lubis (2008) pengaplikasian pupuk di piringan mulai dari jari-jari $50 \mathrm{~cm}$ hingga tepi piringan untuk pupuk Urea dan ZA, sedangkan pupuk lain seperti RP, MOP, NPK, dan Kiserit mulai dari 100-275 cm di piringan.

Tempat pengaplikasian pupuk di Kebun Rambutan ditentukan berdasarkan jenis pupuk, cara aplikasi dan umur tanaman. Jarak penaburan pupuk $\mathrm{N}$ yaitu $50-100 \mathrm{~cm}$ sedangkan pupuk lain $125-150 \mathrm{~cm}$ dari pangkal batang (umur 2-8 tahun). Penaburan pupuk $\mathrm{N}$ pada umur $>8$ tahun diaplikasikan pada jarak $150-200 \mathrm{~cm}$, sedangkan pupuk lain 200-250 cm dari pangkal batang. Peletakkan pupuk dengan cara pocket dilakukan pada jarak $75 \mathrm{~cm}$ (TBM) dan $175 \mathrm{~cm}$ (TM) dari pangkal batang.Hasil pengamatan tepat tempat dapat dilihat pada Tabel 6.

Tabel 6. Hasil uji-t tepat tempat pemupukan NPK Palmo di Kebun Rambutan

\begin{tabular}{cccc}
\hline Ulangan & $\begin{array}{c}\sum \text { Tanaman } \\
\text { yang diamati } \\
\text { (pohon) }\end{array}$ & $\begin{array}{c}\text { Standar } \\
\text { perusahaan } \\
(\mathrm{cm})\end{array}$ & $\begin{array}{c}\text { Jarak aplikasi } \\
\text { pupuk }(\mathrm{cm})\end{array}$ \\
\hline 1 & 75 & 175 & $165.12^{*}$ \\
2 & 75 & 175 & $170.94^{*}$ \\
3 & 75 & 175 & $169.45^{*}$ \\
\hline Rata-rata & & & $168.50^{*}$ \\
\hline
\end{tabular}

Keterangan: *: Berbeda nyata pada uji-t taraf $5 \%$

Berdasarkan hasil pengamatan pada Tabel 6, ketepatan tempat pemupukan NPK Palmo ratarata $168.50 \mathrm{~cm}$. Nilai tersebut menunjukkan adanya perbedaan antara tempat pengaplikasian pupuk NPK Palmo di lapangan dengan standar perusahaan. Hal ini disebabkan oleh ketidaksesuaian lubang pocket, sehingga penabur hanya mengaplikasikan pupuk pada lubang tersebut. Penyelesaian masalah dapat dilakukan dengan memberikan pengarahan dan pengawasan kepada karyawan yang bekerja membuat lubang pocket agar sesuai dengan standar perusahaan.

\section{Kehilangan Pupuk}

Kehilangan pupuk merupakan hilangnya pupuk di lahan sehingga menjadi kendala yang harus dihindari. Menurut Pahan (2007) kehilangan pupuk dapat disebabkan oleh kerusakan karung pupuk akibatnya pupuk tercecer di lahan, pencurian dan disembunyikan di gawangan atau dibuang ke parit. Kehilangan pupuk yang terjadi di Kebun Rambutan disebabkan oleh kerusakan karung pupuk, pembuangan pupuk di parit dan banyaknya pupuk yang tumpah saat pembagian pupuk oleh penabur. Pembantingan karung pupuk saat bongkar muat dari truk menyebabkan terjadinya kerusakan pada karung tersebut. Hasil pengamatan losses dapat dilihat pada Tabel 7.

Tabel 7. Kehilangan pupuk pada pemupukan Urea di Kebun Rambutan

\begin{tabular}{ccccc}
\hline Ulangan & $\begin{array}{c}\text { Jenis } \\
\text { pupuk }\end{array}$ & $\begin{array}{c}\sum \text { Pupuk yang } \\
\text { diaplikasikan } \\
(\mathrm{kg})\end{array}$ & $\begin{array}{c}\text { Losses } \\
(\mathrm{kg})\end{array}$ & \% Losses \\
\hline 1 & Urea & 4348 & 18.32 & 0.42 \\
2 & Urea & 3523 & 12.21 & 0.35 \\
3 & Urea & 4038 & 9.71 & 0.24 \\
\hline Rata-rata & & 3969.67 & 13.41 & 0.34 \\
\hline
\end{tabular}

Berdasarkan pengamatan pada Tabel 7, Rata-rata kehilangan pupuk Urea di lapang kurang dari $1 \%$ yaitu sebesar $0,34 \%$. Kebun Rambutan tidak memiliki standar khusus kehilangan pupuk yang diperbolehkan, namun sebaik mungkin tidak terjadi kehilangan pupuk. Data kehilangan pupuk Urea di Kebun Rambutan menunjukkan terjadinya kerugian sebesar $13.41 \mathrm{~kg}$ dari rata-rata total pemupukan $3969.67 \mathrm{~kg}$. Harga pupuk Urea di pasar sebesar Rp $5000 \mathrm{~kg}^{-1}$, sehingga kerugian yang diterima perusahaan sebesar Rp 67050 blok $^{-1}$ pemupukan. Penyelesaian masalah dapat dilakukan dengan mengusahakan sebaik mungkin agar karung pupuk tidak rusak, melakukan evaluasi setelah melakukan pemupukan, memperketat pengawasan agar tidak terjadi pembuangan pupuk di parit dan tidak terdapat pupuk yang tumpah saat pembagian pupuk oleh penabur, serta memberikan pengarahan dan pemahaman kepada penabur tentang kerugian yang akan diterima perusahaan apabila terjadi kehilangan pupuk.

\section{Prestasi Kerja Penabur}

Jumlah tenaga kerja harus ditentukan dengan baik dan sesuai dengan luas areal yang 
Tabel 8. Prestasi kerja penabur di Kebun Rambutan

\begin{tabular}{ccccccccc}
\hline \multirow{2}{*}{ Ulangan } & \multirow{2}{*}{ Jenis pupuk } & \multirow{2}{*}{$\begin{array}{c}\text { Luas } \\
\text { (ha) }\end{array}$} & \multirow{2}{*}{$\begin{array}{c}\text { Total } \\
\text { (kg) }\end{array}$} & \multirow{2}{*}{$\begin{array}{c}\text { Tenaga kerja } \\
\text { (orang) }\end{array}$} & \multicolumn{2}{c}{ Prestasi kerja } & \multicolumn{2}{c}{ Standar kebun } \\
\cline { 6 - 9 } & & & ha HK $\mathrm{Hg} \mathrm{HK}^{-1}$ & ha HK & $\mathrm{kg} \mathrm{HK}^{-1}$ \\
\hline 1 & Urea & 30.96 & 4.348 & 12 & 2.58 & 362.33 & 2 & 285 \\
3 & Urea & 26.18 & 3.523 & 12 & 2.18 & 293.58 & 2 & 285 \\
\hline Rata-rata & Urea & 29.20 & 4.038 & 12 & 2.43 & 336.50 & 2 & 285 \\
\hline
\end{tabular}

akan dipupuk. Norma prestasi penabur pupuk adalah 2-3.5 ha $\mathrm{HK}^{-1}$ atau $400-500 \mathrm{~kg} \mathrm{HK}^{-1}$. Hal tersebut ditentukan oleh dosis pupuk tanaman ${ }^{-1}$, topografi areal dan keterampilan dari penabur (Pahan, 2007). Dosis pupuk yang rendah mengakibatkan tenaga penabur mengaplikasikan jumlah pupuk yang lebih rendah dibandingkan dengan dosis pemupukan yang tinggi. Tofografi lahan yang berbukit dan bergelombang akan mengakibatkan penabur lebih lama menyelesaikan hancanya. Penentuan jumlah tenaga kerja penabur sangat berpengaruh terhadap prestasi kerja karena berhubungan dengan lamanya waktu pemupukan. Tenaga kerja penabur di Kebun Rambutan adalah tenaga pemborong (buruh harian lepas). Hal ini menyebabkan kesulitan dalam menentukan jumlah tenaga kerja penabur dan kurangnya keterampilan penabur. Prestasi kerja penabur di Kebun Rambutan ditentukan oleh dosis pupuk tanaman-1, jumlah tenaga kerja, dan keterampilan dari penabur. Hasil pengamatan prestasi kera penabur dapat dilihat pada Tabel 8.

Berdasarkan hasil pengamatan pada Tabel 8 , menunjukkan rata-rata prestasi kerja penabur untuk pemupukan Urea sebesar 2.39 ha $\mathrm{HK}^{-1}$ dengan bobot $330,80 \mathrm{~kg} \mathrm{HK}^{-1}$. Nilai tersebut telah memenuhi standar perusahaan yaitu 2 ha $\mathrm{HK}^{-1}$ dengan bobot $285 \mathrm{~kg} \mathrm{HK}^{-1}$. Ketepatan prestasi tersebut disebabkan oleh keterampilan penabur yang cukup baik dan pengarahan sebelum dilakukan pemupukan oleh mandor pupuk dan asisten kebun. Prestasi kerja penabur dapat ditingkatkan dengan menggunakan tenaga penabur tetap karena keterampilannya lebih baik dibandingkan tenaga pemborong.

\section{KESIMPULAN}

Kegiatan penelitian di Kebun Rambutan Sumatera Utara telah meningkatkan pengetahuan dan kemampuan mahasiswa tentang budi daya tanaman kelapa sawit baik secara teknis maupun manajerial, khususnya pemupukan tanaman kelapa sawit. Kebun Rambutan sudah menerapkan konsep 5T (tepat jenis, tepat dosis, tepat waktu, tepat cara dan tepat tempat), kehilangan pupuk dan prestasi kerja penabur. Jenis pupuk yang direkomendasikan oleh kebun yaitu pupuk RP tetapi saat aplikasi di lapangan menggunakan pupuk TSP. Ketepatan dosis pemupukan mencapai $92 \%$. Ketepatan cara pemupukan dengan sistem tabur sebesar $91.56 \%$ sedangkan sistem pocket sebesar $92 \%$. Nilai tersebut telah memenuhi standar perusahaan sebesar $\geq 90 \%$. Kehilangan pupuk di lapangan kurang dari $1 \%$ dengan rata-rata $0.34 \%$. Rata-rata prestasi kerja penabur untuk pemupukan sebesar 2.39 ha $\mathrm{HK}^{-1}$ dengan bobot $330.80 \mathrm{~kg} \mathrm{HK}^{-1}$. Realisasi waktu pemupukan untuk TBM kelapa sawit belum memenuhi standar perusahaan karena masih terdapat beberapa jenis pupuk seperti Urea, RP, Borate (TBM 2016) serta MOP dan Kiserit (TBM 2014) yang tidak diaplikasikan. Rata-rata ketepatan tempat pemupukan sebesar $168.50 \mathrm{~cm}$. Nilai tersebut lebih rendah dibandingkan dengan standar perusahaan sebesar $175 \mathrm{~cm}$.

\section{DAFTAR PUSTAKA}

Bahari, S. 2010. Manajemen pemupukan dan taksasi produksi tandan buah segar (TBS) kelapa sawit di PT. Tunggal Perkasa Plantations ( PT. Astra Agro Lestari, Tbk.) Indragiri Hulu, Riau. [Skripsi]. Institut Pertanian Bogor. Bogor.

[BPS] Badan Pusat statistika. 2014. Produksi tanaman perkebunan menurut propinsi dan jenis tanaman, Indonesia (ton), (2012-2014) .[internet]. [diunduh 2016 Mar 9]. Tersedia pada http://bps.go.id/linkTableDinamis/view/ $\mathrm{id} / 839$.

[Ditjenbun] Direktorat Jenderal Perkebunan. 2015. Luas areal dan produksi kelapa sawit perkebunan rakyat, besar negara, besar swasta nasional dan besar swasta $\operatorname{asing}(\mathrm{PR}+\mathrm{PBN}+\mathrm{PBS}+\mathrm{PBSA}) \quad$ menurut provinsi dan keadaan tanaman. [internet]. [diunduh 2016 Nov 17]. Tersedia pada http://ditjenbun.pertanian.go.id/tinymcpuk/ga mbar/file/statistik.

Hakim, M. 2007. Kelapa Sawit: Teknis Agronomis dan Manajemennya (Tinjauan 
Teoritis dan Praktis). Lembaga Pupuk Indonesia, Jakarta.

Lubis, A.U. 2008. Kelapa sawit (Elaeis guineensis Jacq.) di Indonesia. Pusat Penelitian Kelapa Sawit, Medan.

Masykur. 2013. Pengembangan industri kelapa sawit sebagai penghasil energi bahan bakar alternatif dan mengurangi pemanasan global (studi di Riau sebagai penghasil kelapa sawit terbesar di Indonesia. Jurnal Reformasi. 3(2):96-107.

PPKS. 2005. Pemupukan Kelapa Sawit. Pusat Penelitian Kelapa Sawit, Medan.

Pahan, I. 2007. Panduan Lengkap Kelapa Sawit Manajemen Agribisnis dari Hulu Hingga Hilir. Penebar Swadaya, Medan.
Ryanto, R. 2012. Manajemen pemupukan kelapa sawit (Elaeis guineensis Jacq.) di Pinang Sebatang Estate, PT. Aneka Intipersada, PT. Minamas Politations, Siak, Riau. [Skripsi]. Institut Pertanian Bogor. Bogor.

Saputra, R.A., 2011. Evaluasi pemupukan pada kelapa sawit (Elaeis guineensis Jacq.) di Kebun Radang Seko Banjar Balam, PT Tunggal Perkasa Plantations, Indragiri Hulu, Riau. [Skripsi]. Institut Pertanian Bogor. Bogor.

Walpole, R.E. 1995. Pengantar Statistika. PT Gramedia Pustaka Utama, Jakarta.

Winarna, Darmosarkoro, W., Sutarta, S.E. 2007. Teknologi Pemupukan Tanaman Kelapa Sawit. Pusat Penelitian Kelapa Sawit, Medan. 